\title{
Erratum to: Association mapping of maturity and plant height using SNP markers with the sorghum mini core collection
}

\author{
Hari D. Upadhyaya $\cdot$ Yi-Hong Wang $\cdot$ \\ C. L. L. Gowda $\cdot$ Shivali Sharma
}

Published online: 4 May 2014

C) Springer-Verlag Berlin Heidelberg 2014

Erratum to: Theor Appl Genet (2013) 126:2003-2015

DOI 10.1007/s00122-013-2113-x

Due to an error in the production process, legends of Fig. 1 and Fig. 2 are identical in the original publication. Given below is the correct legend for Fig. 1.

Fig. 1. Cumulative distribution of $p$ values computed from 14,739 SNPs for naïve, Q, PCA, K, QK, and PK association mapping models with sorghum height and maturity. More uniform $p$ value distribution indicates a better model. The lines of naïve and PCA overlap while those from K, QK and PK overlap in both traits.

The online version of the original article can be found under doi:10.1007/s00122-013-2113-x.

H. D. Upadhyaya · C. L. L. Gowda · S. Sharma

Gene Bank, International Crops Research Institute for the SemiArid Tropics (ICRISAT), Patancheru 502 324, Andhra Pradesh, India

Y.-H. Wang ( $\square)$

Department of Biology, University of Louisiana at Lafayette, Lafayette, LA 70504, USA

e-mail: yxw9887@louisiana.edu 